\title{
Phonological activation of category coordinates in spoken word production: Evidence for cascaded processing in English but not in Mandarin
}

\author{
QINGFANG ZHANG \\ Renmin University of China \\ XUEBING ZHU \\ Shanghai International Studies University \\ MARKUS F. DAMIAN \\ University of Bristol
}

Received: December 25, 2016

Accepted for publication: December 15, 2017

\begin{abstract}
ADDRESS FOR CORRESPONDENCE
Qingfang Zhang, Department of Psychology, Renmin University of China, 59 Zhongguancun Street, Haidian District, Beijing, 100872, China. E-mail: qingfang.zhang@ruc.edu.cn
\end{abstract}

\begin{abstract}
A central issue in spoken word production concerns how activation is transmitted from semantic to phonological levels. Recent evidence from studies of speakers of Western languages supports a cascaded view, according to which under certain circumstances, lexical candidates other than the target can activate their corresponding phonological properties. In the current study, we investigated possible differences between English and Mandarin speakers concerning the degree of cascadedness in the production system, based on the broader recent claim that properties of word form encoding might differ according to languages. With English speakers (Experiment 1), we found that when activation of targets and semantic competitors was boosted via a manipulation of semantic context, then concurrently presented "mediated" distractor words (which were phonologically related to a semantic competitor) generated interference. However, no such mediated priming was found in a parallel experiment with Chinese materials and Mandarin speakers (Experiment 2). These results suggest potential fundamental differences across the target languages in how activation is transmitted during lexical access.
\end{abstract}

Keywords: multiple phonological activation; phonological encoding; speech production

Spoken production involves the timely coordination of semantic, syntactic, and phonological properties of the words to be produced. In a word production task such as picture naming, recognition of the object induces activation of conceptual codes. Many models of spoken production make the assumption that a word's semantic

(C) Cambridge University Press 2018 0142-7164/18 
and syntactic properties are represented in a "lemma" representation, and that semantically related lemmas are coactivated based on conceptual input. Activation then proceeds to a word form layer that represents a word's morphological and phonological properties (Dell, 1986; Jescheniak \& Levelt, 1994; Levelt, Roelofs, \& Meyer, 1999; Roelofs, 1992, 1997).

A long-standing debate concerns the temporal coordination of, and interaction between, those information types, and especially how activation is transmitted from lexical nodes to phonological encoding. In the literature, researchers have proposed two opposite possibilities: serial and nonserial models. Serial discrete models (e.g., Levelt et al., 1999) argue that for a given target word, only a single selected lemma spreads its activation to the phonological level, and semantic processing must be completed before phonological processing commences. By contrast, nonserial models such as cascaded models (e.g., Humphreys, Riddoch, \& Quinlan, 1988; Morsella \& Miozzo, 2002) propose that multiple lexical-semantic candidates that are coactivated during retrieval of the target word transmit activation to the phonological level. An even stronger form of nonseriality is proposed by interactive models (e.g., Dell, 1986) in which it is also assumed that transmission of activation between semantic and phonological processes is bidirectional, that is, word form encoding can influence lexical-semantic retrieval. Critically, in serial models, phonological activation is strictly restricted to the target word. By contrast, in nonserial models (both cascaded and interactive), phonological processing begins on the basis of early partial information provided by semantic processes, and any activated concepts and lemma nodes could transmit activation to their corresponding phonological nodes (in interactive models, activation also flows backward through the system). The present study investigates the possibility of multiple phonological activation differing across languages (in our case, English and Mandarin Chinese).

Findings from speech error studies have been taken to argue against a serial, and for an interactive, viewpoint (e.g., Dell, 1986; Dell \& Reich, 1981). Recent findings from error-free spoken word production also argue against a strictly serial, and for a cascaded, processing mode. Much of this evidence is based on demonstrations of "multiple phonological activation"; that is, entries other than the target are activated at the phonological level. For instance, in the "picture-picture interference" task, two line drawings are superimposed in different colors, and speakers name a target picture based on color while attempting to ignore the distractor picture. Morsella and Miozzo (2002) first demonstrated that when target and context picture were phonologically related (e.g., bed-bell), naming latencies were faster than when they were unrelated. The observation of phonological activation of context pictures has been replicated in English (Meyer \& Damian, 2007) as well as in Spanish (Navarrete \& Costa, 2005) and Dutch (Roelofs, 2008). This contradicts a central tenet of serial models of spoken word production (according to which phonological encoding should be restricted to the target only) and is in line with a cascaded view.

At the same time, cascading of activation from the semantic to the phonological level does appear to be restricted. In a variation of the task in which a single colored picture is presented, and speakers name either the object or the color, phonological facilitation is found when colors are named (and objects ignored) but not when objects are named (and colors ignored; e.g., Dumay \& Damian, 2011; Kuipers \& 
La Heij, 2009). This asymmetry suggests that cascading is limited to the "primary" dimension (i.e., the object name) but nontarget properties such as color (or size, as shown more recently by Roux, Bonin, \& Kandel, 2014) do not seem to be processed in a cascaded fashion. Hence, the evidence suggests a "limited cascadedness" view of spoken word production.

Independent of the debate as to whether or not cascadedness is restricted to particular target dimensions (see above), cascaded processing is itself probably quite subtle, such that cascading of nontarget properties is not detectable under all circumstances. This appears to be the case in the popular picture-word interference (PWI) task, in which participants are instructed to name target pictures while ignoring distractor words superimposed on the target. A semantic relationship between target picture and distractor (dog-cat) slows naming relative to an unrelated word, whereas a phonological relationship (cat-cap) speeds up latencies (Glaser \& Düngelhoff, 1984; Schriefers, Meyer, \& Levelt, 1990; Starreveld \& La Heij, 1995). The possibility of cascadedness of nontarget properties can be investigated by using "mediated" distractors, that is, words that are only indirectly related to the target, such as the target picture "dog" paired with a distractor "can," which is phonologically related to the semantic target coordinate "cat." If such mediated distractors were to influence target naming, this would imply that not only the target (in this case, "dog") but also coactivated items (such as "cat") underwent phonological processing. However, mediated distractors appear not to affect target naming latencies in PWI tasks (Damian, 1998; Jescheniak, Hahne, Hoffmann, \& Wagner, 2006; but note that in the latter study, mediated effects were found in children) nor do mediated effects emerge in electrophysiological measures (Jescheniak, Hahne, \& Schriefers, 2003). This suggests that under typical circumstances, cascaded processing of nontarget properties might be too weak to exert a measurable effect. By contrast, mediated priming has been shown with pictures with near-synonymous names such as Schäfer-Hirte (both meaning "shepherd"; Jescheniak \& Schriefers, 1998): when speakers named these pictures with the dominant name, then distractors that were phonologically related to the nondominant name caused interference (see Peterson \& Savoy, 1998, for related findings with regard to synonyms). In the case of objects with near-synonymous names, it appears that both alternatives are phonologically encoded (hence implying cascadedness), with the incorrect alternative being primed by the mediated distractor and hence causing interference.

Assuming that in spoken word production, cascading of activation from semantic to phonological levels is genuine yet subtle, one could surmise that mediated effects will emerge more clearly if the degree of semantic and/or phonological overlap within mediated target/distractor combinations is increased. As outlined above, this is arguably the case with target objects with near-synonymous names such as Schäfer-Hirte (Jescheniak \& Schriefers, 1998) for which the two alternatives are semantically virtually identical. An alternative strategy might be to boost activation at the semantic level via presentation of two semantically related pictures. Oppermann, Jescheniak, Schriefers, and Görges (2010) asked speakers to name, cued by color, one of two spatially separated pictures on a computer screen; in addition, a spoken distractor word was presented. Distractors that were phonologically related to the nontarget picture slowed down target naming latencies, but 
only when the two pictures were semantically related and not when they were unrelated. Accordingly, it is assumed that "there must be a semantics-sensitive mechanism that modulates the information flow in the conceptual-lexical system and that gates the amount of phonological activation" (see Roelofs, 2008, p. 366).

Yet a different approach is to boost the magnitude of phonological activation via presentation of multiple distractor words. Abdel Rahman and Melinger (2008) superimposed two distractor words on a single target pictures, one of which sharing initial segments and the other sharing final segments with a word semantically related to the target. They found significant interference relative to an unrelated condition, consistent with the idea that when sufficiently primed, nontarget alternatives are phonologically activated. Most recently, Melinger and Abdel Rahman (2013) reported that activating a concept associatively related to a target picture via form-related distractor word pairs interfered with naming. For example, naming the target picture "pyramid" was slowed by the presence of the written distractors "camera" and "bagel" (form related to "camel," an associate of "pyramid"), compared to an unrelated distractor combination. Overall, the evidence at present supports a theoretical framework in which activation transmission from semantic to phonological levels is cascaded.

\section{WORD PRODUCTION IN WESTERN AND NON-WESTERN LANGUAGES}

While, as reviewed above, an increasing body of evidence supports cascaded models, the extant research is largely based on Indo-European languages such as English, German, Spanish, and Dutch, and little attention has been paid to the possibility of a different phonological architecture in languages with nonalphabetic scripts. For instance, in the WEAVER model (Roelofs, 1997) word form encoding includes parallel access to phonological segments as well as retrieval of suprasegmental information. The two types of information are subsequently sequentially merged and associated with syllables in an incremental fashion. However, this architecture might not be universal across languages, and it has recently been suggested (O'Seaghdha, 2015; O'Seaghdha, Chen, \& Chen, 2010) that languages differ in the "proximate unit" of phonological encoding (i.e., the primary selectable unit below the word level). In Western languages, phonological segments constitute proximate units, and many priming effects demonstrated in experimental tasks (such as phonological facilitation in PWI tasks, e.g., Glaser \& Düngelhoff, 1984; Schriefers et al., 1990) are based on segmental overlap. However, similar segmental manipulations in experiments conducted on Chinese individuals have resulted in null findings, and instead priming effects are observed with syllabic manipulations only (e.g., Chen, Chen, \& Dell, 2002; Chen, Lin, \& Ferrand, 2003; O'Seaghdha et al., 2010; Verdonschot, Nakayama, Zhang, Tamaoka, \& Schiler, 2013; You, Zhang, \& Verdonschot, 2012). This suggests that in non-Western languages such as Mandarin and Cantonese, syllables (rather than segments) constitute the proximate units. Roelofs (2015) recently provided a first attempt to computationally model such differences between languages concerning phonological encoding.

Potential differences between languages concerning the architecture of phonological encoding might have consequences for the issue of how activation is transmitted from the semantic to the phonological level. We have recently reported 
work that highlights such a difference. For instance, a possible strategy of tackling the serial versus nonserial issue is to apply additive-factors logic (Sternberg, 1969) in a PWI experiment. By factorially crossing semantic and phonological overlap between targets and distractors, one can test for statistical additivity between the two variables. Additivity would be accounted for more easily with a serial model, whereas a statistical interaction would be more in line with a nonserial notion of lexical access. A substantial number of previous studies have demonstrated nonadditivity (i.e., a statistical interaction between semantic and phonological overlap) in such experiments, across various Western languages (e.g., English: Damian \& Martin, 1999; Taylor \& Burke, 2002; Dutch: Starreveld \& La Heij, 1995; French: Bonin \& Fayol, 2000), and this pattern is generally taken to support a nonserial notion. However, with Chinese materials and Mandarin speakers, we (Zhu, Damian, $\&$ Zhang, 2016) found a strictly additive relation between semantic and (syllablebased) phonological relatedness. This pattern is more in line with a serial notion of lexical access, and underscores a potential important difference between Western and non-Western languages concerning phonological encoding.

Further evidence for this claim comes from studies based on electroencephalography (EEG), a method that allows to track access to representational stages before an overt response has commenced. Using a PWI task combined with EEG, Dell'Acqua et al. (2010) found significant effects of semantic and phonological relatedness in the time window of $250-450 \mathrm{~ms}$ post-picture onset, with peak latencies of semantically related distractors $(320 \mathrm{~ms})$ coincided temporally with those of phonologically related distractors $(321 \mathrm{~ms})$. By contrast, with Chinese speakers, we (Zhu, Damian, \& Zhang, 2015) found a semantic effect in a time window of 250-450 ms, which was followed by a phonological effect in a much later time window, at 450-600 ms. Hence, EEG results from Mandarin speakers suggest a temporal dissociation between semantic and phonological stages in Chinese, that is, a serial/sequential pattern. Overall, these results lend some support to the possibility that phonological encoding might differ in important aspects between Western and non-Western languages such as Mandarin.

\section{THE PRESENT STUDY}

In the present study, we further tackled the issue of seriality versus cascadedness in spoken word production, as well as potential differences between Western and non-Western languages, with a novel approach. For our experiments, we reverted back to the use of "mediated" distractors in PWI tasks (distractors that are phonologically related to a semantic competitor of the target object), a manipulation that as summarized above typically results in null findings (e.g., Damian, 1998) but under certain circumstances might render interference, namely, when semantic (e.g., Oppermann et al., 2010) or phonological (e.g., Abdel Rahman \& Melinger, 2008) activation is increased.

In our experiments we manipulated activation at the semantic level with a manipulation of "semantic blocking." In this task, participants repeatedly name a small set of objects within an experimental block. Item sets within blocks are chosen such that they either belong to the same semantic category ("homogeneous" condition) or each picture comes from a different category ("heterogeneous"). The 


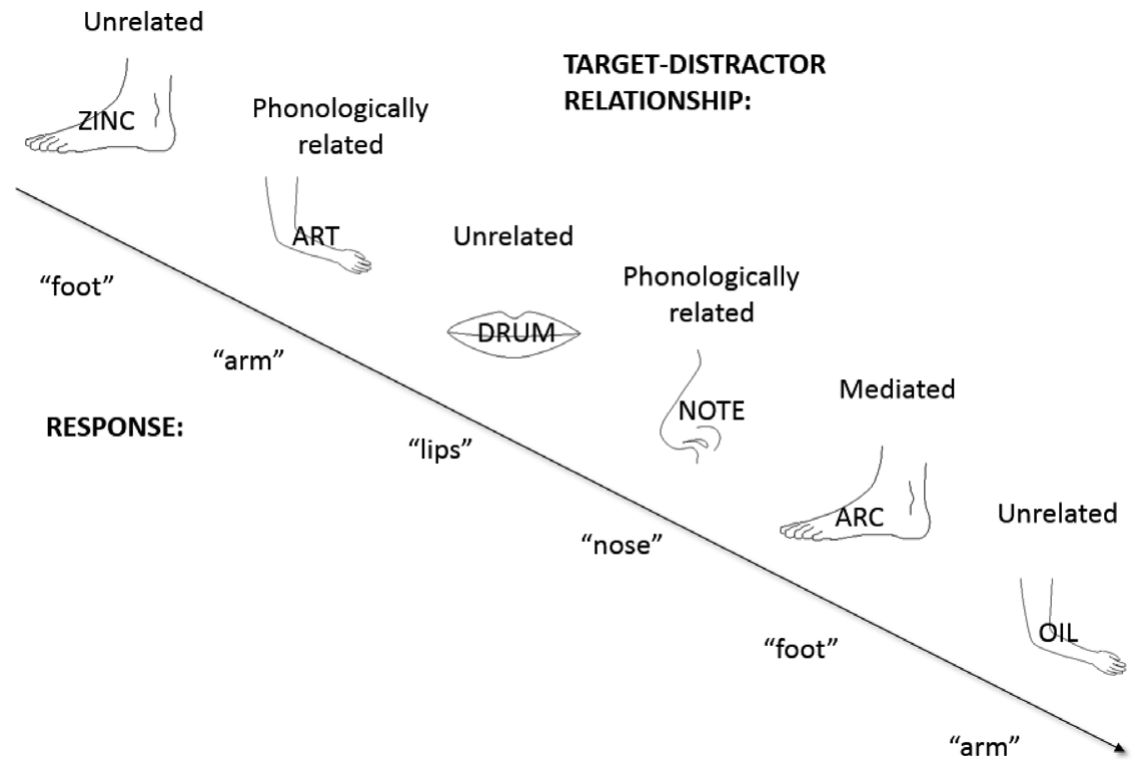

Figure 1. Picture-word interference task combined with semantic blocking: sample trials from a semantically homogeneous block (category: body parts) with unrelated, phonologicaistractor type in English. $* p<.05 ; * * p<.01 ; * * *<.001$.

typical finding is that naming latencies are longer in the homogeneous than in the heterogeneous condition (Abdel Rahman \& Melinger, 2007; Aristei, Melinger, \& Abdel Rahman, 2011; Belke, Meyer, \& Damian, 2005; Damian \& Als, 2005; Damian, Vigliocco, \& Levelt, 2001). Pictures in the same semantic category cause additional activation of the related concepts and their corresponding lexical items, which enhances the competition and delays lemma selection. However, the exact mechanism by which this effect occurs remains somewhat controversial. This issue is less important for our present purposes because regardless of what exactly causes the effect, it is safe to assume that in homogeneous contexts, targets and their semantic competitors are more highly activated than in heterogeneous contexts.

We combined the semantic blocking manipulation with the use of mediated (and other) distractors (note that Aristei et al., 2011, also used semantic blocking in conjunction with a PWI manipulation, but in their case, with semantically related distractor words). On each trial, a target picture was paired with one of three kinds of visual distractor words: unrelated, phonologically related, and mediated (i.e., phonologically related to a semantic competitor). See Figure 1 for a sketch of a "homogeneous" block with various distractors superimposed on target objects. In line with numerous previous findings in the PWI literature, we expected a facilitation effect from phonologically related distractors, and this effect should be of comparable magnitude in semantically heterogeneous and homogeneous contexts. The critical manipulation concerned the "mediated" distractors, which 
on any given trial were unrelated to the target word, but phonologically related to a semantic competitor. Based on existing findings (e.g., Damian, 1998), we predicted that in semantically heterogeneous blocks, mediated distractors should not affect target naming latencies. By contrast, in semantically homogeneous blocks, targets as well as semantic competitors undergo heightened activation, and hence we predicted that here mediated distractors might slow down target naming latencies because distractors of this type will further prime an (already preactivated) potential competitor. We tested these predictions in Experiment 1 with English speakers.

As highlighted in the previous section, there is preliminary support for the claim that phonological encoding in non-Western languages such as Mandarin might differ from Western languages. Specifically, Zhu et al. (2016) presented evidence for a more strictly serial notion of lexical access in Mandarin speakers, and Zhu et al. (2015) demonstrated that the time course of phonological encoding, as measured by EEG, differed from previous results obtained with Western speakers. A possible prediction from these findings is that the mediated effects that we predicted in Experiment 1, restricted to semantically homogeneous contexts, should generally be absent with Mandarin speakers. We tested this possibility in Experiment 2.

\section{EXPERIMENT 1}

\section{Method}

Participants. Twenty-four students (5 male; average age 21.4 years; range $18-31$ years) from the University of Bristol were paid or received course credit for their participation. All were native English speakers and had normal or corrected-tonormal vision.

Materials and design. Sixteen black-and-white line pictures were selected from the standardized picture database of Snodgrass and Vanderwart (1980), including four objects in each of four semantic categories (body parts, furniture, tools, and vehicles). Objects were combined into sets of four in order to form four "homogeneous" and four "heterogeneous" sets: in "homogeneous" blocks, all four pictures were from the same semantic category, whereas in "heterogeneous" blocks, one picture came from each semantic category. All pictures had monosyllabic names.

Each target picture was paired with three distractor words. A phonologically related word was chosen that shared one or more word-initial phonemes $(58 \%$ segmental overlap on average) with the picture name (i.e., target: "train"; distractor: "trail"). A mediated word was chosen that shared one or more word-initial phonemes (54\% shared segments on average) with a picture name from the same semantic category as the target (i.e., target: "train," distractor: "bulb," which is phonologically related to "bus"). An unrelated distractor word was selected that stood in no obvious relationship to the target (i.e., "goose" as a distractor). Distractors in each condition were statistically matched for length in phonemes and letters, and written frequency based on the normative information reported in the Neighborhood Watch program (Davis, 2005). An additional four pictures were selected as practice items. 
Zhang et al.: Multiple phonological activation

The experimental design included the variables semantic context (homogeneous and heterogeneous) and distractor type (phonologically related, mediated, and unrelated) as within-participants and within-items variables. Eight blocks that each contained four target pictures, presented repeatedly, were constructed. Within each block, each target was repeated 4 times under each distractor type. Therefore, each of the four targets occurred 12 times for a total 48 trials in each block. The order of items within one block was pseudorandomized for each participant with the constraint that a particular target and the first phoneme of a target name was never the same on consecutive trials. Four homogeneous blocks and four heterogeneous blocks were constructed, yielding a total of 384 trials. Homogeneous and heterogeneous blocks were presented in alternating orders, and the order of different block lists was counterbalanced according to a Latin square design.

We assessed the degree of semantic relatedness between semantic competitors of mediated distractors and target names, and the one between unrelated words and target names by 16 native English speakers ( 8 males, age from 19 to 26 years old) who did not take part in Experiment 1. Target picture names were paired with their corresponding semantic competitors of mediator distractor words and unrelated distractor words, respectively. The word pairs were presented in random order, and pictures from the same category were avoided in the consecutive trials. The word pairs were rated on a 5-point scale, with 5 indicating that word pairs were highly semantically related and 1 indicating that word pairs were semantically unrelated. The average degree of semantic relatedness was $1.74(S D=0.42)$ with a range of 1.25 to 2.69 between unrelated distractors and target names, and was 3.63 ( $S D=$ 0.45 ) with a range of 3.00 to 4.26 between semantic competitors and target names across subjects. A paired-sample $t$ test indicated a significant difference between two semantic relatedness degrees, $t(15)=14.85, p<.001$.

Apparatus. Stimuli were presented via an IBM-compatible computer on a 17-inch monitor using DMDX 3.0 (Forster \& Forster, 2003). Pictures were standardized to a size of approximately $6 \times 6 \mathrm{~cm}$ and displayed at the center of the screen. Distractor words were presented in 22-point Times New Roman font, centrally superimposed on the target pictures. Naming latencies were measured from target onset using a digital voice key.

Procedure. Participants were tested individually in a soundproof room. They were seated approximately $60 \mathrm{~cm}$ from a computer screen. Participants were asked to familiarize themselves with the experimental stimuli by viewing each target for $3000 \mathrm{~ms}$ with the correct name printed underneath. Then, participants were instructed to name individual target pictures as fast and accurately as possible while attempting to ignore superimposed distractor words. In a subsequent practice block, four additional pictures paired with unrelated distractor words were presented twice. Then, eight experimental blocks of 48 trials each were carried out.

Each trial involved the following sequence: A fixation point (*) was presented in the middle of the screen for $500 \mathrm{~ms}$, followed by a blank screen for $500 \mathrm{~ms}$. Then, the target picture and distractor word were presented simultaneously on the screen. Target pictures and distractor words disappeared when participants initiated 


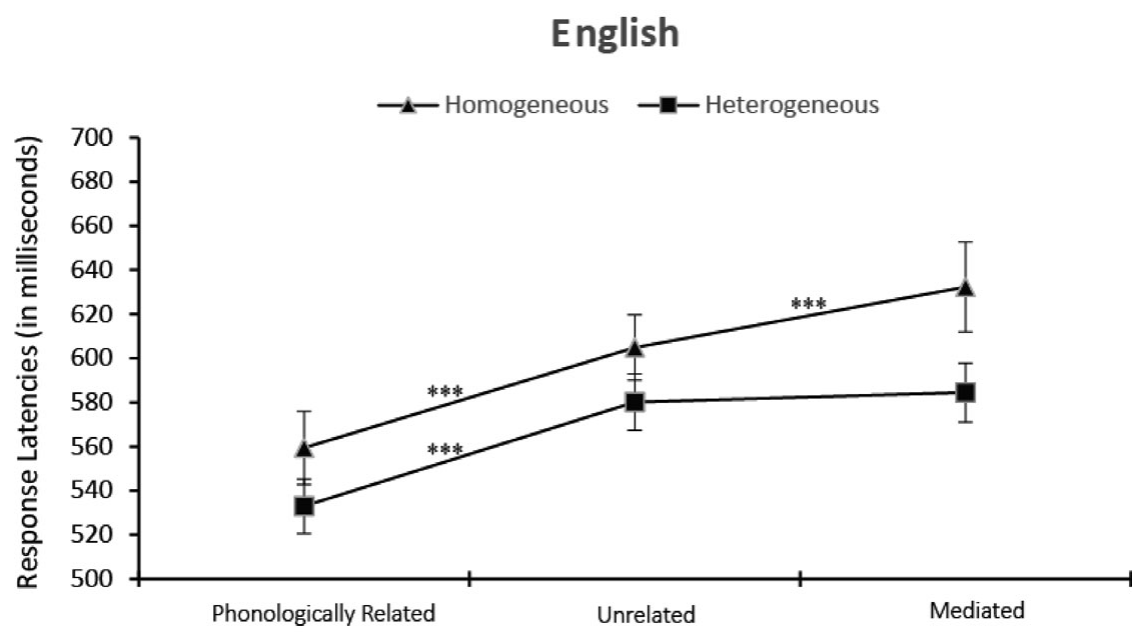

Distractor Types

Figure 2. Mean pictures naming latencies and standard errors dependent on semantic context and distractor type in English. * $p<.05 ;{ }^{* *} p<.01 ; * * *<.001$.

a voice response. An intertrial interval of $1500 \mathrm{~ms}$ was included in each trial. The experiment took about $40 \mathrm{~min}$ in total.

\section{Results of Experiment 1}

Data from incorrect responses and other responses caused by microphone errors (3.4\%), naming latencies longer than $2000 \mathrm{~ms}$ or shorter than $200 \mathrm{~ms}(0.3 \%)$, and those deviating by more than $3 S D$ from a participant's mean $(1.28 \%)$ were removed from the response time analyses. Furthermore, it is well known from previous studies that the effect of semantic context differs between first presentation of an object within a block and all subsequent presentations, with either little or no effect on first presentation (e.g., Aristei et al., 2011; Belke et al., 2005; Damian \& Als, 2005), or a facilitatory effect (e.g., Abdel Rahman \& Melinger, 2007). Because this pattern is of little interest to the purpose of our current study, we removed data from the first presentation of an object paired with each kind of distractor within each block. ${ }^{1}$ Error rates were low (overall 1.6\%) and thus were not analyzed further.

Figure 2 presents mean picture naming latencies and standard errors by semantic context and distractor type. As expected, a sizable semantic blocking effect is visible, as well as priming from phonologically related distractors. Mediated distractors have no effect in the semantically heterogeneous context, but generate numerical interference in the homogeneous context.

Analyses of variance (ANOVAs) were conducted on the response latencies, with participants $\left(F_{1}\right)$ or items $\left(F_{2}\right)$ as random factors and semantic context and distractor type as within-participants and within-items variables. A significant effect of semantic context was found, $F_{1}(1,23)=27.07, M S E=1,445, p<.001$, 
Zhang et al.: Multiple phonological activation

$\eta_{\mathrm{p}}{ }^{2}=0.54 ; F_{2}(1,15)=20.62, M S E=1,330, p<.001, \eta_{\mathrm{p}}{ }^{2}=0.58$, and a significant effect of distractor type, $F_{1}(2,46)=104.9, M S E=479, p<.001, \eta_{\mathrm{p}}{ }^{2}=0.82$; $F_{2}(2,30)=56.96, M S E=597, p<.001, \eta_{\mathrm{p}}{ }^{2}=0.79$. The interaction between semantic context and distractor type was significant, $F_{1}(2,46)=3.86, M S E=$ $519, p<.05, \eta_{\mathrm{p}}{ }^{2}=0.14 ; F_{2}(2,30)=9.61, M S E=136, p<.001, \eta_{\mathrm{p}}{ }^{2}=0.39$.

In order to assess the effects of phonological and mediated overlap separately, as well as to explore potential interactions with the semantic context manipulation, we conducted two additional analyses in which the unrelated condition and one of the two related conditions (phonologically or mediated) was included whereas the other related condition was removed. First, ANOVAs with semantic context (homogeneous vs. heterogeneous) and phonological relatedness (related vs. unrelated) as within-participants and within-items factors revealed a significant effect of semantic context, $F_{1}(1,23)=13.43, M S E=1,164, p<.001, \eta_{\mathrm{p}}{ }^{2}=0.37$; $F_{2}(1,15)=11.01, M S E=1,015, p<.01, \eta_{\mathrm{p}}{ }^{2}=0.42$, a significant effect of distractor type, $F_{1}(1,23)=126.74, M S E=407, p<.001, \eta_{\mathrm{p}}{ }^{2}=0.85 ; F_{2}(1,15)$ $=57.19, M S E=616, p<.001, \eta_{\mathrm{p}}{ }^{2}=0.79$, but no interaction between semantic context and phonological relatedness, $F_{1}(1,23)<1, M S E=207, p>.1 ; F_{2}(1$, $15)<1, M S E=181, p>$. 1 . Planned $t$ tests for the phonological facilitation in the homogeneous context $\left(M_{\text {diff }}=-45 \mathrm{~ms}\right)$ were significant, $t_{1}(23)=-7.59, p<$ $.001 ; t_{2}(15)=-5.37, p<.001$, and so were $t$ tests for phonological facilitation in the heterogeneous context $\left(M_{\text {diff }}=-47 \mathrm{~ms}\right), t_{1}(23)=-12.07, p<.001 ; t_{2}(15)=$ $-9.5, p<.001$. Hence, we found the expected phonological facilitation, and this effect was independent of semantic context.

Second, ANOVAs with semantic context (homogeneous or heterogeneous) and mediated relatedness (related vs. unrelated) as within-participants and within-items factors revealed a significant effect of semantic context, $F_{1}(1,23)=28.03, M S E$ $=1,124, p<.001, \eta_{\mathrm{p}}{ }^{2}=0.55 ; F_{2}(1,15)=24.97, M S E=887, p<.001, \eta_{\mathrm{p}}{ }^{2}$ $=0.63$, as well a significant effect of distractor type, $F_{1}(1,23)=16.06, M S E=$ $377, p<.001, \eta_{\mathrm{p}}{ }^{2}=0.41 ; F_{2}(1,15)=8.14, M S E=491, p<.05, \eta_{\mathrm{p}}{ }^{2}=0.35$. A significant interaction of semantic context and distractor type was obtained, $F_{1}$ $(1,23)=6.44, M S E=503, p<.05, \eta_{\mathrm{p}}{ }^{2}=0.22 ; F_{2}(1,15)=30.21, M S E=68$, $p<.001, \eta_{\mathrm{p}}{ }^{2}=0.67$. Planned $t$ tests for the mediated effect in the homogeneous context $\left(M_{\text {diff }}=-27 \mathrm{~ms}\right)$ were significant, $t_{1}(23)=3.82, p<.00 ; t_{2}(15)=4.82$, $p<.001$, but $t$ tests for the mediated effect in the heterogeneous context $\left(M_{\mathrm{diff}}=\right.$ $4 \mathrm{~ms})$ were not, $t_{1}(23)=0.92, p=.37 ; t_{2}(15)=0.72, p=.48$. Hence, mediated distractors had an effect only in a semantically homogeneous context.

To evaluate the effect size of the phonological and the mediated effect, we calculated their Cohen $d$ for the homogeneous and heterogeneous conditions separately. For the phonological effect, Cohen $d$ was 0.76 (heterogeneous) and 0.60 (homogeneous). For the mediated effect, Cohen $d$ was 0.06 (heterogeneous) and 0.31 (homogeneous).

\section{Discussion of Experiment 1}

The main findings of Experiment 1 were as follows. First, in line with numerous recent studies (e.g., Abdel Rahman \& Melinger, 2007; Aristei et al., 2011; Belke et al., 2005; Damian et al., 2001), a semantic context effect was observed: pictures 
were named more slowly in semantic homogeneous than in heterogeneous blocks. This effect likely arises from boosted semantic activation among response items when named in the homogeneous, compared to the heterogeneous, context. Second, we found a facilitation effect from phonologically related distractors, a finding that is again predicted by numerous existent studies (e.g., Damian \& Martin, 1999; Schriefers et al., 1990; Starreveld \& La Heij, 1995) and shows that English speakers benefit from segment-sized (i.e., subsyllabic) phonological overlap between distractor and target. Third and most important, we found an interfering effect of mediated distractors, but this effect was present only in a semantically homogeneous, but not in a heterogeneous context. This finding demonstrates multiple phonological activation (i.e., phonological activation of a nontarget lexical entry) but only when targets and competitors are already preactivated via the semantic context in which they occur. Hence, the results add to the evidence suggesting that activation transmission to the phonological level is restricted. The combination of PWI with semantic blocking provides a task that is sensitive to otherwise relatively weak multiple phonological activation.

Experiment 2 used the same experimental manipulation, but now with Chinese materials and native Mandarin speakers. The semantic context effect, as well as the facilitatory effect of phonologically related distractors, should be similar across languages. However, based on previous results (e.g., Zhu et al., 2015, 2016), we predicted that the mediated effect that emerged in the first experiment, but only under a semantically homogeneous context, should be absent in the second experiment.

\section{EXPERIMENT 2}

\section{Method}

Participants. Twenty undergraduate students (10 male; average age 21.4 years; range 19-25 years) from Beijing Forest University and China Agricultural University were paid for their participation. All were native Mandarin Chinese speakers and had normal or corrected-to-normal vision.

Materials and design. Twenty-five black-and -white line pictures were selected from a standardized picture database in Chinese (Zhang \& Yang, 2003), including five objects from each of five semantic categories (animals, body parts, clothing, fruits, and tools). All pictures had disyllabic names. The objects were combined into sets of five in order to form five homogeneous and five heterogeneous blocks, with the latter ones including one item in each semantic category.

Each target picture was paired with three disyllabic distractor words. A phonologically related word was chosen that shared the first syllable but not the tone with the picture name (i.e., target: 袋鼠, /dai4shu3/, kangaroo; distractor: 不徒, /dai3tu2/, gangster). A mediated word was chosen that shared the first syllable but not the tone with the first character of a picture name from the same semantic category as the target (i.e., target "kangaroo," distractor: 席子, /xi2zi5/, “mat," which is phonologically related to 犀牛, /xi1niu2/, "rhinoceros"). An unrelated word was selected that stood in no obvious relationship to the target (i.e., 枕头 
/zhen3tou2/, pillow). Distractors in each condition were statistically matched for number of strokes and written frequency based on normative information reported in the database of the Chinese Lexicon (Chinese Linguistic Data Consortium, 2003). An additional two drawings were selected as practice items.

The experimental design included the variables semantic context (homogeneous and heterogeneous) and distractor type (phonologically related, mediated, and unrelated) as within-participants and within-items variables. Ten blocks that each contained five pictures were constructed. Within each block, each target was repeated 4 times in each distractor type. Therefore, each of the five targets occurred 12 times for a total 60 trials in each block. The order of items within one block was pseudorandomized for each participant with the constraint that a particular target and the first phoneme of a target name was never the same on consecutive trials. Five homogeneous blocks and five heterogeneous blocks were constructed, yielding a total of 600 trials. Homogeneous and heterogeneous blocks were presented in alternating orders, and the order of different block lists was counterbalanced according to a Latin square design.

We also assessed the degree of semantic relatedness between semantic competitors of mediated distractors and target names, and the one between unrelated words and target names by 16 native Chinese speakers ( 4 males, age from 18 to 45 years old) who did not take part in the Experiment 2. An identical rating procedure as the one in English was used. The average degree of semantic relatedness was $1.61(S D=0.42)$ with a range of 1.00 to 2.64 between unrelated distractors and target names, and was $3.75(S D=0.52)$ with a range of 3.08 to 4.68 between semantic competitors and target names across subjects. A paired-sample $t$ test indicated a significant difference between two semantic relatedness degrees, $t(15)$ $=15.25, p<.001$. For semantic competitors of the mediator distractor words, an independent-sample $t$ test indicated there was no significant difference between English and Chinese speakers, $t(30)=-0.73, p=.47$, reflecting that the degree of semantic relatedness between target names and semantic competitors were similar in English and Chinese.

Apparatus. The experiment was performed using E-Prime Professional Software (Version 1.1; Psychology Software Tools). Pictures were standardized to a size of approximately $6 \times 6 \mathrm{~cm}$ and displayed at the center of the screen. Distractor words were presented in 30-point Song font, centrally superimposed on the target pictures. Naming latencies were measured from target onset using a digital voice key, connected with the computer via a PST serial response box.

Procedure. The procedure was identical to Experiment 1, with the exception that 10 experimental blocks of 60 trials each were presented. The experiment took about $60 \mathrm{~min}$ in total per participant.

\section{Results of Experiment 2}

Data from incorrect responses $(0.9 \%)$, and other responses such as mouth clicks $(0.6 \%)$, naming latencies longer than $2000 \mathrm{~ms}$ or shorter than $200 \mathrm{~ms}(0.008 \%)$, and those deviating by more than $3 S D$ from a participant's mean (1.51\%) were 


\section{Mandarin}

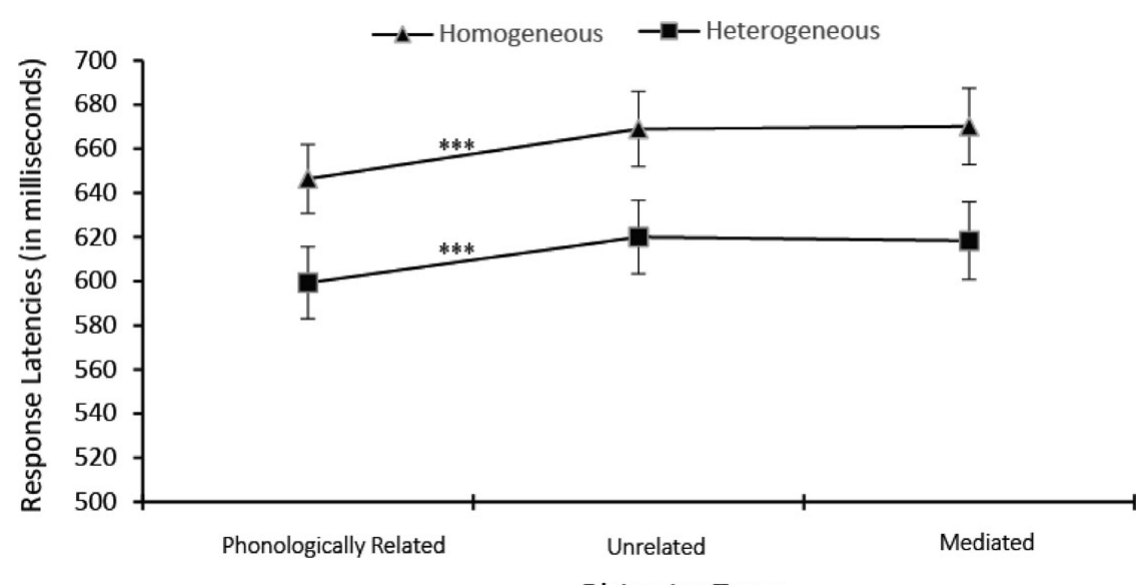

Distractor Types

Figure 3. Mean pictures naming latencies and standard errors dependent on semantic context and distractor type in Mandarin. * $p<.05 ; * * p<.01 ; * * *<.001$.

removed from all analyses. As in Experiment 1, data of the first presentation of an object paired with three different kinds of distractors within each block were removed from the analysis. Error rates were low (overall $<1 \%$ ) and thus were not analyzed further.

Figure 3 presents mean picture naming latencies and standard errors by semantic context and distractor type. As in the first experiment, the expected semantic blocking effect, as well as facilitation from phonologically related distractors, is visible. By contrast, mediated distractors appear to have little or no effect, and this is the case both in the semantically homogeneous and the heterogeneous contexts.

ANOVAs were conducted on the response latency means, with participants $\left(F_{1}\right)$ or items $\left(F_{2}\right)$ as random factors and semantic context and distractor type as withinparticipants and within-items variables. A significant effect of sSemantic context was found, $F_{1}(1,19)=78.87, M S E=924, p<.001, \eta_{\mathrm{p}}{ }^{2}=0.81 ; F_{2}(1,24)=$ $70.40, M S E=1321, p<.001, \eta_{\mathrm{p}}{ }^{2}=0.75$, as well a significant effect of distractor type, $F_{1}(2,38)=29.62, M S E=209, p<.001, \eta_{\mathrm{p}}{ }^{2}=0.61 ; F_{2}(2,48)=28.64$, $M S E=276, p<.001, \eta_{\mathrm{p}}{ }^{2}=0.54$. No interaction was found between these two variables, $F_{1}(2,38)=0.39, p=.68 ; F_{2}(2,48)=0.57, p=.57$. Because the absence of this interaction contrasts with the results from the first experiment, and in order to establish the likelihood of the null hypothesis being true, we further conducted a Bayesian analysis with the method suggested by Rouder, Morey, Speckman, and Province (2012) using JASP software (Love et al., 2015). The results revealed that the model with only the two main effects was superior to the full model including the interaction, with a Bayes factor of $B F_{10}=5.36$, which implies that the null hypothesis is more than five times more likely than the alternative hypothesis. According to the classification suggested by Jeffreys 
(1961), this constitutes "substantial" evidence for the null hypothesis (i.e., the finding of no interaction is true).

In order to assess the effects of phonological and mediated overlap separately, planned $t$ tests analogous to those conducted in the first experiment were carried out. These showed that the phonological facilitation effect in the semantically homogeneous context $\left(M_{\mathrm{diff}}=-23 \mathrm{~ms}\right.$ ) was significant, $t_{1}(19)=-5.18, p<.001$; $t_{2}(24)=-5.40, p<.001$, as was the effect in the semantically heterogeneous context $\left(M_{\text {diff }}=-21 \mathrm{~ms}\right), t_{1}(19)=-5.04, p<.001 ; t_{2}(24)=-7.86, p<.001$. By contrast, mediated distractors had no effect under the semantically homogeneous context $\left(M_{\text {diff }}=1 \mathrm{~ms}\right), t_{1}(19)=0.42, p=.68 ; t_{2}(24)=0.41, p=.68$, nor under the semantically heterogeneous context $\left(M_{\text {diff }}=-2 \mathrm{~ms}\right), t_{1}(19)=-0.34, p=.74$; $t_{2}(24)=-0.20, p=.84$. To further support the null finding concerning the effects of mediated distractors, we conducted Bayesian analysis using JASP software as mentioned above. Using the Jeffreys-Zellner-Siow Bayes-factor paired-sample $t$ test (Rouder, Speckman, Sun, Morey, \& Iverson, 2009), our result showed a Bayes factor $B F_{10}$ of 3.99 for the mediated effect in homogeneous blocks, and 4.08 for heterogeneous blocks, suggesting that the null hypothesis is approximately four times more likely than the alternative hypothesis. Again, the results provide substantial support for the null hypothesis over the alternative.

To evaluate the effect size of the phonological and the mediated effect, we calculated their Cohen $d$ for the homogeneous and heterogeneous conditions separately. For the phonological effect, Cohen $d$ was 0.28 (heterogeneous) and 0.31 (homogeneous). For the mediated effect, Cohen $d$ was 0.02 (heterogeneous) and 0.01 (homogeneous).

\section{Discussion of Experiment 2}

The results of Experiment 1, with English speakers, had suggested multiple phonological activation, as indicated by an interfering impact of mediated distractors that was restricted to a semantically homogeneous context. The goal of Experiment 2 was to determine whether this was also the case with Mandarin speakers. The results showed the expected semantic context effect (we are not aware of previous studies that had used semantic blocking in Chinese, but prima facie this effect should be independent of response language) as well as phonological facilitation from related distractors (Wong \& Chen, 2008; Zhang, Chen, Weekes, \& Yang, 2009; Zhang \& Yang, 2005; Zhao, La Heij, \& Schiller, 2012). However, no mediated effect was found, a finding that clearly diverges from the results of the first experiment with English speakers. Although semantic activation was boosted when objects were named in a context of other items belonging to the same category (hence giving rise to the semantic blocking effect), mediated distractors that were phonologically related to one of the semantic alternatives showed no effect. The absence of a mediated effect in Mandarin cannot be attributed to insensitivity of the task we used since we obtained mediated effects in Experiment 1 (subtle differences in design and materials between the two experiments will be discussed in detail below). Hence, we argue that the discrepancy between the results obtained from English and Mandarin speakers concerning mediated effect arises from differences with regard to phonological encoding. 
In the experiments reported here, we revisited the issue of information transmission from semantic to phonological levels in spoken word production. Combining the semantic blocking paradigm with a picture-word interference manipulation, the critical question was whether "mediated" distractors (words that are phonologically related to a semantic competitor of the target object) exert an effect on target naming latencies. If so, the results could lend further support to the claim that information transmission in spoken production is "cascaded" (e.g., Kuipers \& La Heij, 2009; Morsella \& Miozzo, 2002; Navarrete \& Costa, 2005) and at least under some circumstances involves the activation of multiple phonological entries. In Experiment 1, we used English speakers and materials, and (besides the expected effects of semantic context and phonologically related distractors), we found mediated priming, but only in the semantically homogeneous, and not in the heterogeneous, context. In Experiment 2, we used Chinese materials and native Mandarin speakers in a design that was otherwise largely analogous to the first study. Again, we found semantic context effects and facilitation from phonologically related distractors. Critically, however, mediated priming was found under neither the semantically homogeneous nor the heterogeneous context.

The English results are generally in line with those from previous studies conducted on speakers of Western languages. As summarized above, there is accumulating evidence for a "cascaded" view of lexical access in speaking: it is principally possible for nontarget lexical entries to cascade activation to the phonological level, but cascadedness is generally so subtle that it cannot be detected in all tasks and circumstances. Hence, for instance, mediated distractors in PWI tasks (words that are phonologically related to a semantic competitor of the target object) show no effect on target naming under usual circumstances (e.g., Damian, 1998). Only when either semantic or phonological activation is boosted relative to a "standard" case (e.g., when two semantically related pictures are presented, as in Oppermann et al., 2010, or when a single picture is paired with two phonologically related distractors, as in Abdel Rahman \& Melinger, 2008) do mediated distractors show an effect. This is in line with our findings from English speakers: mediated distractors had no effect in semantically heterogeneous blocks, but they generated interference when presented in semantically homogeneous blocks in which semantic activation of targets and competitors is presumably increased.

The results from Mandarin speakers are perhaps more surprising. In a largely analogous experiment, the expected semantic blocking and phonological facilitation effects were found. This is reassuring as there is no obvious reason why these effects should be affected by target language. However, no mediated effects were found in this experiment. At face value, the absence of mediated effects might be interpreted as evidence for serial information transmission in Mandarin. If so, our results would suggest a fundamental difference between the target languages with regard to phonological encoding: weak cascadedness in English, but strictly serial transmission in Mandarin.

We highlight the fact that the absence of a mediated effect in spoken Mandarin is fully compatible with two sets of results that we recently reported: Zhu et al. (2016) factorially crossed semantic and phonological relatedness in a PWI 
task with Mandarin speakers, and in contrast to numerous previous findings from speakers of Western languages, the two types of relatedness exerted a strictly additive relationship in Mandarin. Based on additive factors logic, this can be interpreted as indicating serial/discrete information transmission between semantic and phonological levels. Zhu et al. (2015) provided further evidence for a serial model via EEG and showed that with Mandarin speakers, semantic and phonological stages emerged in sequential corresponding time windows, which conflicts with comparable EEG studies conducted on speakers of Western languages where both stages appeared largely at the same time. Both sets of results are in line with the absence of a mediated effect in our present Experiment 2, and point toward a serial transmission mode in Mandarin spoken word production.

Is it possible that the difference observed in the mediated condition between English and Chinese arose at the conceptual level? Perhaps speakers of the two languages exhibit differences in which they mentally represent the semantic categories that we used (tools, furniture, body parts, etc.), and the presence or absence of a mediated effect hinges on the underlying conceptual representations. However, studies on such semantic categories have suggested strong similarity across languages (e.g., Bowerman, 1973; Brown, 1973; Slobin, 1970, 1973), and accordingly, the chosen categories and exemplars in our experiments successfully evoked the semantic blocking effect numerously reported before, and in both languages. The semantic effect in our task was numerically more pronounced in Chinese than in English, which should render it more likely that mediated effects should be observed in the former compared to the latter language. However, instead, we found mediated effects only in English but not in Chinese. This makes a conceptual origin of the differences in the mediated condition unlikely. ${ }^{2}$

It is acknowledged that there are subtle differences in materials and manipulations across the two studies that might hamper a clear interpretation of the results. These are as follows: in Experiment 1, we used four semantic categories with four examples each; in Experiment 2, there were five categories with five exemplars. This variation is unlikely to make a difference and is within the limits of the existing literature (e.g., Damian et al., 2001, used a $5 \times 5$ design, whereas Damian $\&$ Als, 2005, used $4 \times 4$ ). Due to the difference in categories/exemplars between the two experiments, but given the identical repetition of targets within each block (12), this resulted in 384 trials per participant in the first experiment, but 600 trials in the second. It is unlikely that the overall length of the experiments would have influenced the results (e.g., Maess, Friederici, Damian, Meyer, \& Levelt, 2002, reported a semantic blocking experiment with a total of 1,200 trials).

In addition, form overlap in our study was manipulated in terms of both orthography and phonology for the English stimuli, but exclusively in terms of phonology for the Chinese stimuli. ${ }^{3}$ This discrepancy arose from constraints on stimulus selection; ideally, one would use either English distractors that are only phonologically but not orthographically related or Chinese distractors that share orthographic properties such as the first character with the target. Unfortunately, both strategies are difficult to implement: in alphabetic languages such as English, sound and spelling are necessarily confounded, so it is difficult or impossible to find word pairs that are phonologically but not orthographically related. In Chinese, if a distractor and a target share the first orthographic character, semantic associations between the 


\section{ENGLISH}

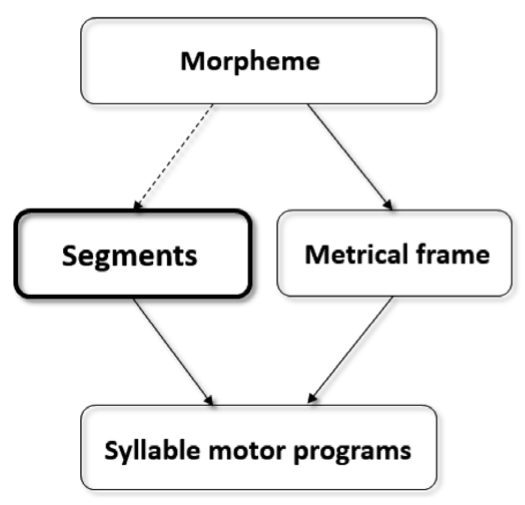

MANDARIN

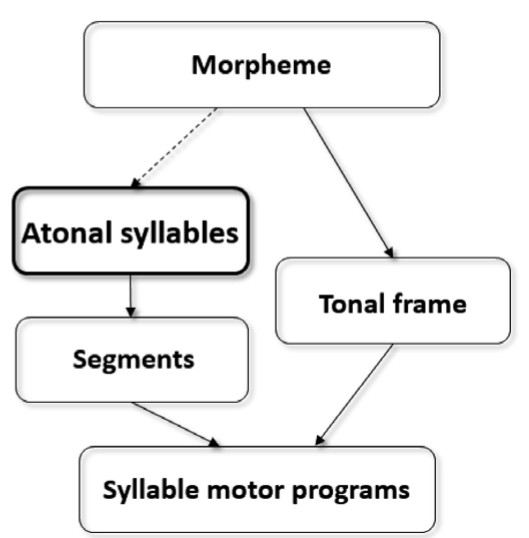

Figure 4. Sketch of phonological encoding in English and Mandarin. Proximate unites are highlighted.

two are unavoidable. One could also consider repeating our two experiments with spoken, rather than written, distractors, but again this is problematic as due to the prevalent homophony in Mandarin, isolated spoken words are often difficult to disambiguate. Considering these potential factors, the different findings in English and Chinese should be interpreted cautiously and need to be investigated further.

A further variation that is difficult to avoid is that in the English experiment, targets and distractors were monosyllabic, whereas in Chinese they were disyllabic. This arises from the statistics of the target languages: within the constraints of the semantic blocking paradigm, it would be difficult to identify adequate disyllabic targets in English, or monosyllabic targets in Chinese. In addition, phonological overlap was segmental in the English experiment, but syllabic in Chinese. Again, this inconsistency cannot be avoided: because targets are monosyllabic in English, phonological overlap is necessarily subsyllabic and segmental. In Mandarin, by contrast, subsyllabic segmental overlap in PWI tasks results in little or no priming (e.g., Wong \& Chen, 2008, 2009); hence, we had to define overlap syllabically (here, in terms of the initial syllable overlapping between target and distractor). It is worth highlighting that the relative degree of phonological overlap between target and distractor was comparable across the two experiments: average segmental overlap was 54\% in Experiment 1 (see Materials section), and syllabic overlap was $50 \%$ in Experiment 2 (one out of two syllables was shared between disyllabic targets and distractors).

What are the theoretical implications of the current findings with regard to models of phonological encoding across languages? Due to the sparsity of available results on word production in non-Western languages, theoretical accounts of the results from our experiments are necessarily speculative. Figure 4 shows a rough processing sketch of word form encoding across the two target languages, 
loosely adapted from Roelofs (2015) and O'Seaghdha (2015). "Proximate units," defined as the primary selectable unit below the word level by O'Seaghdha, Dell, and Schwartz (2010), are highlighted. Note that the Mandarin model contains a segmental layer, despite the fact that behavioral experiments that manipulated segmental overlap have tended to result in null findings (e.g., Chen et al., 2002; Wong \& Chen, 2008, 2009; see also Verdonschot et al., 2011, for results from Japanese). Segments nevertheless probably contribute to phonological encoding because segmentally based speech errors are found in spoken Chinese (e.g., Chen, 1993); note also that Qu, Damian, and Kazanina (2012; see also Yu, Mo, \& Mo, 2014) presented EEG evidence for the presence of segmental effects in Mandarin speakers despite behavioral null findings, which further warrants inclusion of such a segmental layer in the model.

Given that phonological overlap in our experiments was defined at the proximate unit level (i.e., segmental in English but based on atonal syllables in Mandarin), there is no obvious reason why information transmission from morpheme to proximate unit level should be cascaded in English, but serial in Mandarin. Nevertheless, this is what our results suggest. Hence, processing along the critical pathway (shown in dotted lines in Figure 4) could fundamentally differ between languages. This account is admittedly post hoc, and it is not obvious why this should be the case. Perhaps this is because in Western languages, relatively few segments combine to form a potentially unlimited number of lexical items, whereas in Mandarin, the number of syllables is much larger and so a discrete activation makes sense for syllables whereas the process is more continuous for segments.

In all three relevant sets of results (Zhu et al., 2015, 2016; and the current findings), phonological overlap was defined in terms of overlapping atonal syllables (e.g., the target "cherry," /ying1tao2/ was paired with the distractor "profit," /ying2li4/). Given that in PWI tasks, segmental overlap in (Cantonese) Chinese by itself does not generate priming (Wong \& Chen, 2008, 2009), we attributed the phonological facilitation in our Experiment 2 to the "proximate unit" layer of atonal syllables. Is it possible that this assumption is incorrect, and phonological facilitation perhaps took place at the level of the tonally specified syllable? If so, this could explain the statistical additivity between semantic interference and phonological facilitation reported in Zhu et al. (2016), as well as the relatively late time window under which phonological effects appeared in the EEG results reported by Zhu et al. (2015). Such an account would have to explain why the coactivation of similar (but tonally mismatching) syllables generates behavioral priming. Under the assumption that segments and tonal syllables are bidirectionally connected, perhaps the activation of the distractor syllable /ying2/ could prime, via shared segments, the target syllable /ying1/.

Although this scenario is not impossible, we believe that similar effects would then be predicted for Western languages as well: for example, if both the target object "cat" and a phonologically related distractor "cap" activate their corresponding syllables and activation is shared between them via segmental overlap, then we should also find syllabic priming in English and other Western languages. However, this is not the case (e.g., Schiller, 1998, 2000; Schiller, Costa, \& Colomé, 2002), nor does the prediction agree with EEG studies of spoken word production (see above) that have shown a "late" time window of phonological effects only in 
Mandarin, but not in Western languages. Furthermore, it is interesting to note that the WEAVER model of word form encoding (Levelt et al., 1999; Roelofs, 1997) stipulates that access to syllable program nodes is competitive. Hence, the prediction from this framework is that coactivation of similar syllables should hinder, rather than facilitate, access to the correct target syllable. This clearly conflicts with the fact that phonological overlap in PWI generally results in facilitation.

Clearly, further research is required to resolve this issue, and we acknowledge the need for alternative approaches concerning how the phonological properties of a target language could affect semantic-to-phonological transmission. Especially, other phonological properties such as neighborhood density (Peramunage, Blumstein, Myers, Goldrick, \& Baese-Berk, 2011), the role of the relatively low number of atonal syllables and unique properties of tones in Chinese (Roelofs, 2015), need to be investigated directly in the future.

To summarize, the results of the present study suggest that in English spoken word production, nontarget lexical entries can under certain circumstances activate their corresponding phonological properties, supporting a notion of lexical access in which information transmission from semantic to phonological layers is cascaded. This pattern dovetails with a rising number of findings from various tasks and conducted with speakers of Western languages. By contrast, in Mandarin word production, no such evidence for cascadedness was found, and information transmission appeared more strictly serial. This discrepancy highlights potential fundamental differences in phonological encoding across target languages. The combination of semantic blocking and picture-word interference used here and previously (Aristei et al., 2011) offers new possibilities for investigating the underlying mechanisms of spoken word production. 
Zhang et al.: Multiple phonological activation

\section{APPENDIX A}

Table A.1. Materials used in Experiment 1

\begin{tabular}{lccc}
\hline \hline & \multicolumn{3}{c}{ Distractor } \\
Target & Phonologically related & Mediated & Unrelated \\
\cline { 2 - 4 } $\begin{array}{c}\text { Body parts } \\
\text { arm }\end{array}$ & art & link & oil \\
foot & fool & arc & zinc \\
lips & lift & node & drum \\
nose & note & food & inch \\
Furniture & & & \\
bed & bell & storm & yolk \\
chair & cheese & belt & judge \\
desk & debt & chart & owl \\
stool & staff & deaf & dream \\
Tools & & & \\
Axe & act & rain & egg \\
Drill & drift & ash & earth \\
Hoe & hope & drink & vest \\
Rake & race & home & thumb \\
Vehicles & & & \\
bus & bump & card & lawn \\
car & cast & slit & doll \\
Sled & slot & trump & noon \\
train & trail & bulb & goose \\
\hline \hline
\end{tabular}




\section{APPENDIX B}

Table B.1. Materials used in Experiment 2

\begin{tabular}{|c|c|c|c|}
\hline \multirow[b]{2}{*}{ Target } & \multicolumn{3}{|c|}{ Distractor } \\
\hline & Phonologically related & Mediated & Unrelated \\
\hline \multicolumn{4}{|l|}{ Animals } \\
\hline 犀牛 & 习惯 & 扮演 & 括号 \\
\hline (/xi1niu2/, rhinoceros) & (/xi2guan4/, habit) & (/ban4yan3/, act) & (/kuo4hao4/, bracket) \\
\hline 斑马 & 伴奏 & 石灰 & 迷宫 \\
\hline (/ban1ma3/, zebra) & (/ban4zou4/, obbligato) & (/shi2hui1/, lime) & (/mi2gong1/, maze) \\
\hline 骆驼 & 萝卜 & 傣族 & 开关 \\
\hline (/luo4tuo5/, camel) & (/luo2bo5/, radish) & (/dai3zu2/, Dai people) & (/kai1guan1/, switch) \\
\hline 狮子 & 时光 & 螺丝 & 蘑菇 \\
\hline (/shi1zi5/, lion) & (/shi2guang $1 /$, time) & (/luo2si1/, screw) & (/mo2gu5/, mushroom) \\
\hline 袋鼠 & 歹徒 & 席子 & 枕头 \\
\hline (/dai4shu3/, kangaroo) & (/dai3tu2/, gangster) & (/xi2zi5/, mat) & (/zhen3tou5/, pillow) \\
\hline 犀牛 & 习惯 & 扮演 & 括号 \\
\hline \multicolumn{4}{|l|}{ Body parts } \\
\hline 鼻子 & 比喻 & 醉酒 & 空调 \\
\hline (/bi2zi5/, nose) & (/bi3yu4/, metaphor) & (/zui4jiu3/, drunkenness) & (/kong1tiao $2 /$, air-condition) \\
\hline 耳朵 & 而今 & 岩石 & 屏幕 \\
\hline (/er3duo5/, ear) & (/er2jin1/, now) & (/yan2shi2/, stone) & (/ping2mu4/, screen) \\
\hline 胳膊 & 隔扇 & 笔画 & 池塘 \\
\hline (/ge1bo5/, arm) & (/ge2shan4/, partition) & (/bi3hua4/, stroke) & (/chi2tang2/, pond) \\
\hline 嘴唇 & 罪犯 & 革职 & 墨水 \\
\hline (/zui3chun2/, lips) & (/zui4fan4/, criminal) & (/ge2zhi2/, dismiss) & (/mo4shui3/, ink) \\
\hline 眼睛 & 严寒 & 儿童 & 秋千 \\
\hline (/yan3jing5/, eye) & (/yan2han2/, chilliness) & (/er2tong2/, child) & (/qiu1qian1/, swing) \\
\hline \multicolumn{4}{|l|}{ Clothing } \\
\hline $\begin{array}{c}\text { 围巾 } \\
\text { (/wei2jin1/, shawl) }\end{array}$ & $\begin{array}{c}\text { 位移 } \\
\text { (/wei4yi2/, displacement) }\end{array}$ & $\begin{array}{c}\text { 贸易 } \\
\text { (/mao4yi4/, trade) }\end{array}$ & $\begin{array}{c}\text { 钢琴 } \\
\text { (/gang1qin2/, piano) }\end{array}$ \\
\hline
\end{tabular}




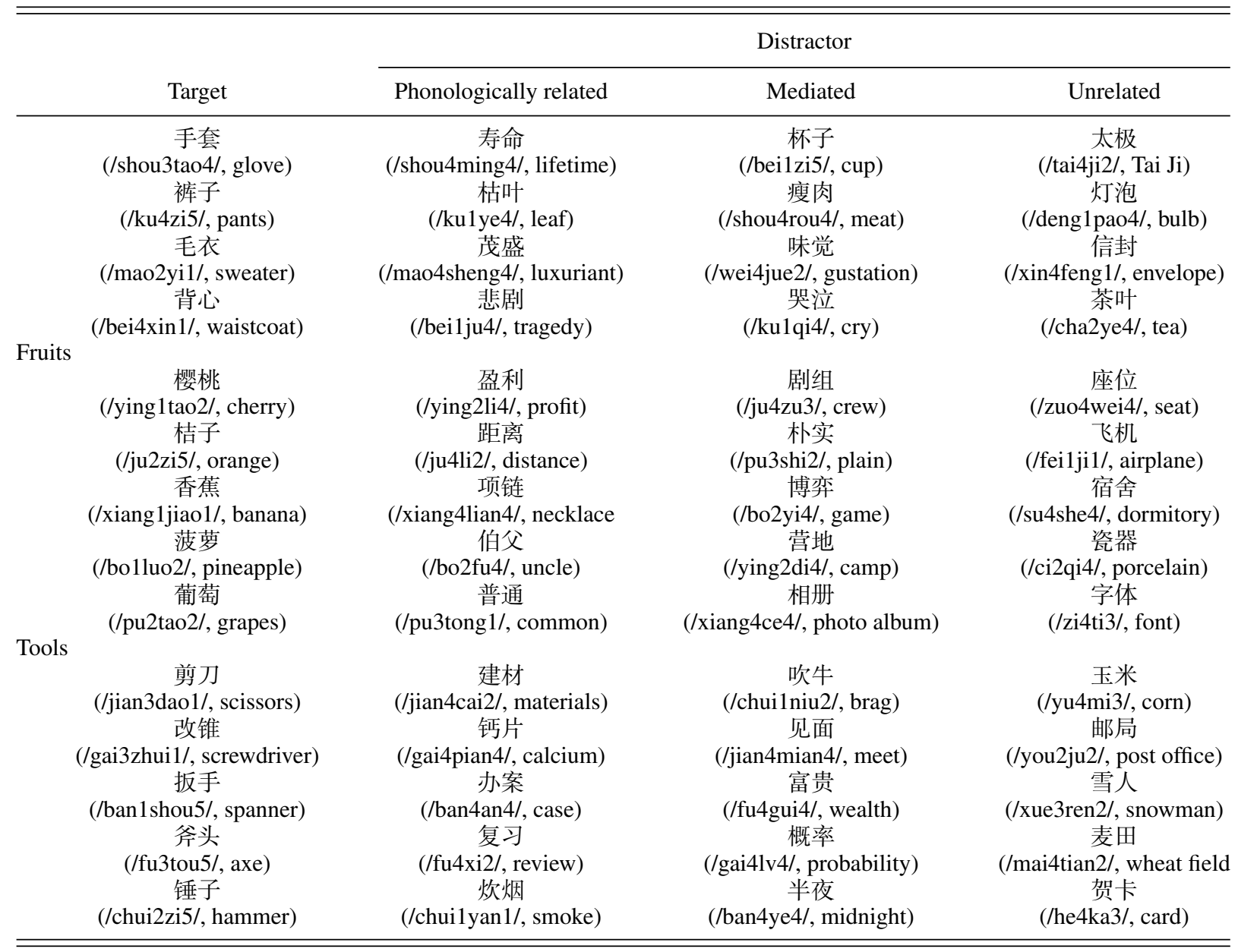


Zhang et al.: Multiple phonological activation

\section{ACKNOWLEDGMENTS}

This research was supported by the National Natural Science Foundation of China under Grant 31471074, and the Key Project of the Beijing Social Science Foundation under grant 16YYA006 (to Q.Z.).

\section{NOTES}

1. In a number of previous studies (e.g., Aristei et al., 2011; Belke et al., 2005; Damian $\&$ Als, 2005) the effect of repetition/cycle was explicitly included in the experimental design. However, in the current experiments, the design is already reasonably complex, and in the interest of clarity, we limited our analyses to those most economically designed to assess our predictions.

2. We thank an anonymous reviewer for bringing this point to our attention.

3. Again, we thank an anonymous reviewer for bringing up this issue.

\section{SUPPLEMENTARY MATERIAL}

To view supplementary material for this article, please visit https://doi.org/10. $1017 /$ S0142716418000024

\section{REFERENCES}

Abdel Rahman, R., \& Melinger, A. (2007). When bees hamper the production of honey: Lexical interference from associates in speech production. Journal of Experimental Psychology: Learning, Memory, and Cognition, 33, 604-614.

Abdel Rahman, R., \& Melinger, A. (2008). Enhanced phonological facilitation and traces of concurrent word form activation in speech production: An object-naming study with multiple distractors. Quarterly Journal of Experimental Psychology, 61, 1410-1440.

Aristei, S., Melinger, A., \& Abdel Rahman, R. (2011). Electrophysiological chronometry of semantic context effects in language production. Journal of Cognitive Neuroscience, 23, 1567-1586.

Belke, E., Meyer, A. S., \& Damian, M. F. (2005). Refractory effects in picture naming as assessed in a semantic blocking paradigm. Quarterly Journal of Experimental Psychology: Human Experimental Psychology, 58, 667-692.

Bonin, P., \& Fayol, M. (2000). Writing words from pictures: What representations are activated, and when? Memory \& Cognition, 28, 677-689.

Bowerman, M. (1973). Early syntactic development: A cross-linguistic study with special reference to Finnish. Cambridge: Cambridge University Press.

Brown, R. (1973). A first language: The early stages. Cambridge, MA: Harvard University Press.

Chen, J.-Y. (1993). A small corpus of speech errors in Mandarin Chinese and their classification. World of Chinese Language, 69, 26-41 (in Chinese).

Chen, J.-Y., Chen, T.-M., \& Dell, G. S. (2002). Word-form encoding in Mandarin Chinese as assessed by the implicit priming task. Journal of Memory and Language, 46, 751-781.

Chen, J.-Y., Lin, W.-C., \& Ferrand, L. (2003). Masked priming of the syllable in Mandarin Chinese syllable production. Chinese Journal of Psychology, 45, 107-120.

Chinese Linguistic Data Consortium. (2003). 现代汉语通用词表 [Chinese lexicon] (CLDC-LAC2003-001). Beijing, China: Tsinghua University, State Key Laboratory of Intelligent Technology and Systems, and Chinese Academy of Sciences, Institute of Automation.

Damian, M. F. (1998). Semantic and phonological factors in speech production: Evidence from pictureword interference experiments (Unpublished doctoral dissertation, Rice University). 
Zhang et al.: Multiple phonological activation

Damian, M. F., \& Als, L. C. (2005). Long-lasting semantic context effects in the spoken production of object names. Journal of Experimental Psychology: Learning, Memory, and Cognition, 31, $1372-1384$.

Damian, M. F., \& Martin, R. C. (1999). Semantic and phonological codes interact in single word production. Journal of Experimental Psychology: Learning, Memory, and Cognition, 25, 345361.

Damian, M. F., Vigliocco, G., \& Levelt, W. J. M. (2001). Effects of semantic context in the naming of pictures and words. Cognition, 81, B77-B86.

Davis, C. J. (2005). N-Watch: A program for deriving neighborhood size and other psycholinguistic statistics. Behavior Research Methods, 37, 65-70.

Dell, G. S. (1986). A spreading-activation theory of retrieval in sentence production. Psychological Review, 93, 283-321.

Dell, G. S., \& Reich, P. A. (1981). Stages in sentence production: An analysis of speech error data. Journal of Verbal Learning and Verbal Behavior, 20, 611-629.

Dell'Acqua, R., Sessa, P., Peressotti, F., Mulatti, C., Navarrete, E., \& Grainger, J. (2010). ERP evidence for ultra-fast semantic processing in the picture-word interference paradigm. Frontiers in Psychology, 1, 177.

Dumay, N., \& Damian, M. F. (2011). A word-order constraint in single-word production? Failure to replicate Janssen, Alario, and Caramazza (2008). Psychological Science, 22, 559-561.

Forster, K. I., \& Forster, J. C. (2003). DMDX: A windows display program with millisecond accuracy. Behavior Research Methods, Instruments and Computers, 35, 116-124.

Glaser, W. R., \& Düngelhoff, F. J. (1984). The time course of picture word interference. Journal of Experimental Psychology: Human Perception and Performance, 10, 640-654.

Humphreys, G. W., Riddoch, M. J., \& Quinlan, P. T. (1988). Cascade processes in picture identification. Cognitive Neuropsychology, 5, 67-104.

Jeffreys, H. (1961). Theory of probability (3rd ed.). Oxford: Oxford University Press.

Jescheniak, J. D., Hahne, A., Hoffmann, S., \& Wagner, V. (2006). Phonological activation of category coordinates during speech planning is observable in children but not in adults: Evidence for cascaded processing. Journal of Experimental Psychology: Learning, Memory, and Cognition, $32,373-386$.

Jescheniak, J. D., Hahne, A., \& Schriefers, H. (2003). Information flow in the mental lexicon: Evidence from event-related brain potentials. Cognitive Brain Research, 15, 261-276.

Jescheniak, J. D., \& Levelt, W. J. M. (1994). Word frequency effects in speech production: Retrieval of syntactic information and of phonological form. Journal of Experimental Psychology: Learning, Memory, and Cognition, 20, 824-843.

Jescheniak, J. D., \& Schriefers, H. (1998). Discrete serial versus cascaded processing in lexical access in speech production: Further evidence from the coactivation of near-synonyms. Journal of Experimental Psychology: Learning, Memory, and Cognition, 24, 1256-1274.

Kuipers, J., \& La Heij, W. (2009). The limitations of cascading in the speech production system. Language and Cognitive Processes, 24, 120-135.

Levelt, W. J. M., Roelofs, A., \& Meyer, A. S. (1999). A theory of lexical access in speech production. Behavioral and Brain Sciences, 22, 1-75.

Love, J., Selker, R., Marsman, M., Jamil, T., Dropmann, D., Verhagen, A. J., . . Wagenmakers, E.-J. (2015). JASP (Version 0.7)[Computer software]. Retrieved from https:jasp-stats.org

Maess, B., Friederici, A. D., Damian, M., Meyer, A. S., \& Levelt, W. J. (2002). Semantic category interference in overt picture naming: Sharpening current density localization by PCA. Journal of Cognitive Neuroscience, 14, 455-462.

Melinger, A., \& Abdel Rahman, R. (2013). Lexical selection is competitive: Evidence from indirectly activated semantic associates during picture naming. Journal of Experimental Psychology: Learning, Memory, and Cognition, 39, 348-364.

Meyer, A. S., \& Damian, M. F. (2007). Activation of distractor names in the picture-picture interference paradigm. Memory and Cognition, 35, 494-503. 
Zhang et al.: Multiple phonological activation

Morsella, E., \& Miozzo, M. (2002). Evidence for a cascade model of lexical access in speech production. Journal of Experimental Psychology: Learning, Memory, and Cognition, 28, 555563.

Navarrete, E., \& Costa, A. (2005). Phonological activation of ignored pictures: Further evidence for a cascade model of lexical access. Journal of Memory and Language, 53, 359-377.

Oppenheim, G. M., Dell, G. S., \& Schwartz, M. F. (2010). The dark side of incremental learning: A model of cumulative semantic interference during lexical access in speech production. Cognition, 114, 227-252.

Oppermann, F., Jescheniak, J. D., Schriefers, H., \& Görges, F. (2010). Semantic relatedness among objects promotes the activation of multiple phonological codes during object naming. Quarterly Journal of Experimental Psychology, 63, 356-370.

O'Seaghdha, P. G. (2015). Across the great divide: Proximate units at the lexical-phonological interface. Japanese Psychological Research, 57, 4-21.

O'Seaghdha, P. G., Chen, J.-Y., \& Chen, T.-M. (2010). Proximate units in word production: Phonological encoding begins with syllables in Mandarin Chinese but with segments in English. Cognition, 115, 282-302.

Peramunage, D., Blumstein, S. E., Myers, E. B., Goldrick, M., \& Baese-Berk, M. (2011). Phonological neighborhood effects in spoken word production: An fMRI study. Journal of Cognitive Neuroscience, 23, 593-603.

Peterson, R. R., \& Savoy, P. (1998). Lexical selection and phonological encoding during language production: Evidence for cascaded processing. Journal of Experimental Psychology: Learning, Memory, and Cognition, 24, 539-557.

Qu, Q. Q., Damian, M. F., \& Kazanina, N. (2012) Sound-sized segments are significant for Mandarin speakers. Proceedings of the National Academy of Sciences of the United States of America, 109, 14265-14270.

Roelofs, A. (1992). A spreading-activation theory of lemma retrieval in speaking. Cognition, 42, 107142.

Roelofs, A. (1997). The WEAVER model of word-form encoding in speech production. Cognition, 64, 249-284.

Roelofs, A. (2008). Tracing attention and the activation flow in spoken word planning using eye movements. Journal of Experimental Psychology: Learning, Memory, and Cognition, 34, 353368.

Roelofs, A. (2015). Modeling of phonological encoding in spoken word production: From Germanic languages to Mandarin Chinese and Japanese. Japanese Psychological Research, 57, 22-37.

Rouder, J. N., Morey, R. D., Speckman, P. L., \& Province, J. M. (2012). Default Bayes factors for ANOVA designs. Journal of Mathematical Psychology, 56, 356-374.

Rouder, J. N., Speckman, P. L., Sun, D., Morey, R. D., \& Iverson, G. (2009). Bayesian $t$ tests for accepting and rejecting the null hypothesis. Psychonomic Bulletin \& Review, 16, 225-237.

Roux, S., Bonin, P., \& Kandel, S. (2014). The "BIG BIRD" of the "YELLOW YOUNG" man: Do nontarget properties cascade? Quarterly Journal of Experimental Psychology, 67, 763-784.

Schiller, N. O. (1998). The effect of visually masked syllable primes on the naming latencies of words and pictures. Journal of Memory and Language, 39, 484-507.

Schiller, N. O. (2000). Single word production in English: The role of subsyllabic units during phonological encoding. Journal of Experimental Psychology: Learning, Memory, and Cognition, 26, 512-521.

Schiller, N. O., Costa, A., \& Colomé, A. (2002). Phonological encoding of single words: In search of the lost syllable. Laboratory Phonology, 7, 35-59.

Schriefers, H., Meyer, A. S., \& Levelt, W. J. M. (1990). Exploring the time course of lexical access in language production: Picture-word interference studies. Journal of Memory and Language, $29,86-102$. 
Zhang et al.: Multiple phonological activation

Slobin, D. I. (1970). Universals of grammatical development in children. In G. B. Flores D'Arcais \& W. J. M. Levelt (eds), Advances in psycholinguistics. Amsterdam: North-Holland, 174-186.

Slobin, D. I. (1973). Cognitive prerequisites for the development of grammar. In C. A. Ferguson \& D. I. Slobin (eds), Studies of child language development. New York: Holt, Rinehart \& Winston, 175-208.

Snodgrass, J. C., \& Vanderwart, M. (1980). A standardized set of 260 pictures: Norms for names agreement, image agreement, familiarity, and visual complexity. Journal of Experimental Psychology: Human Learning and Memory, 6, 174-215.

Starreveld, P. A., \& La Heij, W. (1995). Semantic interference, orthographic facilitation, and their interaction in naming tasks. Journal of Experimental Psychology: Learning, Memory, and Cognition, 21, 686-698.

Sternberg, S. (1969). The discovery of processing stages: Extensions of Donders' method. Acta Psychologica, 30, 276-315.

Taylor, J. K., \& Burke, D. M. (2002). Asymmetric aging effects on semantic and phonological processes: Naming in the picture-word interference task. Psychology and Aging, 17, 662-676.

Verdonschot, R. G., Kiyama, S., Tamaoka, K., Kinoshita, S., La Heij, \& Schiller, N. O. (2011). The functional unit of Japanese word naming: Evidence from masked priming. Journal of Experimental Psychology: Learning, Memory, and Cognition, 37, 1458-1473.

Verdonschot, R. G., Nakayama, M., Zhang, Q., Tamaoka, K., \& Schiller, N. O. (2013). The proximate unit of Chinese-English bilinguals: Proficiency matters. PLOS ONE, 8, e61454. doi:10.1371/journal.pone.0061454

Wong, A. W.-K., \& Chen, H.-C. (2008). Processing segmental and prosodic information in Cantonese word production. Journal of Experimental Psychology: Learning, Memory, and Cognition, 34, $1172-1190$.

Wong, A. W.-K., \& Chen, H.-C. (2009). What are effective phonological units in Cantonese spoken word planning? Psychonomic Bulletin \& Review, 16, 888-892.

You, W., Zhang, Q., \& Verdonschot, R. G. (2012). Masked syllable priming effects in word and picture naming in Chinese. PLOS ONE, 7, e46595.

Yu, M., Mo, C., \& Mo, L. (2014). The role of phoneme in Mandarin Chinese production: Evidence from ERPs. PLOS ONE, 9, e106486.

Zhang, Q., Chen, H.-C., Weekes, B. S., \& Yang, Y. (2009). Independent effects of orthographic and phonological facilitation on spoken word production in Mandarin. Language and Speech, 52, 113-126.

Zhang, Q., \& Yang, Y. (2003). The determiners of picture naming latency. Acta Psychologica Sinica, 35, 447-454 ( in Chinese).

Zhang, Q., \& Yang, Y. (2005). The phonological planning unit in Chinese monosyllabic word production. Psychological Science, 28, 374-378 (in Chinese).

Zhao, H., La Heij, W., \& Schiller, N. O. (2012). Orthographic and phonological facilitation in speech production: New evidence from picture naming in Chinese. Acta Psychologica, 139, 272-280.

Zhu, X., Damian, M. F., \& Zhang, Q. (2015). Seriality of semantic and phonological processes during overt speech in Mandarin as revealed by event-related brain potentials. Brain and Language, $144,16-25$.

Zhu, X., Zhang, Q., \& Damian, M. F. (2016). Additivity of semantic and phonological effects: Evidence from speech production in Mandarin. Quarterly Journal of Experimental Psychology, 69, 22852304. 